\title{
Comparison of functional outcomes in elderly who have sustained a minor trauma with or without head injury: a prospective multicenter cohort study
}

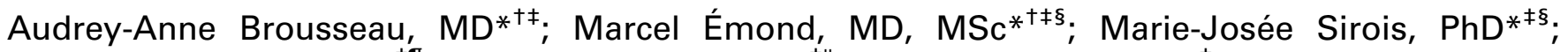
Raoul Daoust, MD, MSc ${ }^{\ddagger \pi}$; Lauren E. Griffith, $\mathrm{PhD}^{\ddagger \|}$; Eddy Lang, MD, MSc ${ }^{\ddagger * *}$; Jacques Lee, MD, $\mathrm{MSc}^{\ddagger \dagger \dagger}$; Jeffrey J. Perry, MD, MSc ${ }^{\ddagger \ddagger \ddagger \S \S ; ~ M a r i e-C h r i s t i n e ~ O u e l l e t, ~ P h D ~}{ }^{\text {ITIIII; }}$, René Verreault, MD, $\mathrm{PhD}^{* \star \S}$; Simon Berthelot, MD, MSc ${ }^{+\ldots l l}$; Éric Mercier, MD, MSc ${ }^{+\ldots l l l}$; Nadine Allain-Boulé, MSc ${ }^{* *}$; Valérie Boucher, BA*; Pier-Alexandre Tardif, MA, MSc ${ }^{\prime \prime \prime \prime}$; Natalie Le Sage, MD, PhD ${ }^{\dagger \neq \| l I I}$

\section{ABSTRACT}

Objectives: The consequences of minor trauma involving a head injury (MT-HI) in independent older adults are largely unknown. This study assessed the impact of a head injury on the functional outcomes six months post-injury in older adults who sustained a minor trauma.

Methods: This multicenter prospective cohort study in eight sites included patients who were aged 65 years or older, previously independent, presenting to the emergency department (ED) for a minor trauma, and discharged within 48 hours. To assess the functional decline, we used a validated test: the Older Americans' Resources and Services Scale. The cognitive function of study patients was also evaluated. Finally, we explored the influence of a concomitant injury on the functional decline in the MT-HI group.

Results: All 926 eligible patients were included in the analyses: $344 \mathrm{MT}-\mathrm{HI}$ patients and 582 minor trauma without head injury. After six months, the functional decline was similar in both groups: $10.8 \%$ and $11.9 \%$, respectively $(R R=$ 0.79 [95\% Cl: $0.55-1.14]$ ). The proportion of patients with mild cognitive disabilities was also similar: $21.7 \%$ and $22.8 \%$, respectively ( $\mathrm{RR}=0.91$ [95\% $\mathrm{Cl}: 0.71-1.18]$ ). Furthermore, for the group of patients with a MT-HI, the functional outcome was not statistically different with or without the presence of a co-injury ( $\mathrm{RR}=1.35$ [95\% Cl: 0.71-2.59]).

Conclusion: This study did not demonstrate that the occurrence of a MT-HI is associated with a worse functional or cognitive prognosis than other minor injuries without a head injury in an elderly population, six months after injury.

\section{RÉSUMÉ}

Objectifs: Les conséquences d'un traumatisme mineur impliquant une blessure à la tête dans la population gériatrique autonome sont largement inconnues. Cette étude en a évalué l'impact en termes de conséquences fonctionnelles six mois après le trauma.

Méthodes: Pour être inclus dans cette cohorte prospective multicentrique de huit sites différents, les patients devaient: être âgés de 65 ans ou plus, être autonomes avant la blessure, avoir consulté au département d'urgence pour un traumatisme mineur et avoir été libérés de I'hôpital dans les 48 heures. Pour évaluer le déclin fonctionnel, un test validé a été utilisé:l'échelle Older Americans' Resources and Services. La fonction cognitive a également été mesurée. Finalement, nous avons exploré l'influence d'une blessure concomitante sur le déclin fonctionnel dans le groupe de patients ayant subi un trauma mineur à la tête.

Résultats: Les 926 patients éligibles ont été inclus dans les analyses: 344 patients avec trauma à la tête et 582 traumas mineurs sans trauma à la tête. Après six mois, le déclin fonctionnel était similaire dans les deux groupes, $10,8 \%$ et $11,9 \%$ respectivement ( $R R=0,79$ [IC 95\%: 0,55 à 1,14$]$ ).

From the *Axe Santé des Populations et Pratiques Optimales en santé, Unité de recherche en vieillissement, Centre de recherche du CHU de Québec, Québec, QC; ${ }^{\dagger}$ Département de Médecine Familiale et Médecine d’Urgence, Université Laval, Québec, QC; ${ }^{\ddagger}$ The Canadian Emergency Department Team Initiative, Québec, $\mathrm{OC} ;{ }^{\S}$ Centre de recherche du CHU de Québec et Centre d'Excellence sur le Vieillissement de Québec, Québec, QC; "Hôpital du Sacré-Cœur de Montréal, Université de Montréal, Montréal, QC; "Department of Clinical Epidemiology and Biostatistics, McMaster University, Hamilton, ON; ${ }^{*}$ Cumming School of Medicine, University of Calgary, Calgary, AB; ${ }^{\dagger+}$ Department of Emergency Services, Clinical Epidemiology Unit, Sunnybrook Health Sciences, Toronto, ON; ${ }^{\ddagger \ddagger}$ Department of Emergency Medicine, School of Epidemiology,

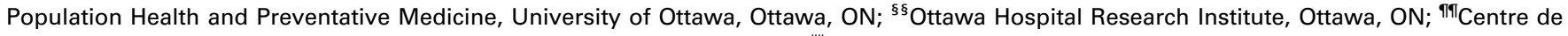
Recherche et Centre Hospitalier Universitaire de Québec, Québec, QC; and '"'Axe Santé des Populations et Pratiques Optimales en santé, Unité de recherche en Traumatologie - Urgence - Soins Intensifs, Centre de recherche du CHU de Québec, Québec, QC

Correspondence to: Natalie Le Sage, Université Laval, Centre de recherche du CHU de Québec - Université Laval, Axe Santé des Population et Pratique Optimales en Santé, 1401, $18^{\mathrm{e}}$ rue, Québec, QC, Canada, G1J 1Z4; E-mail: natalie.lesage@fmed.ulaval.ca 
La proportion de participants démontrant un déficit cognitive léger était également similaire, $21,7 \%$ et $22,8 \%$ respectivement (RR =0,91 [IC 95\%: 0,71 à 1,18]). En outre, pour le sousgroupe de patients ayant subi une blessure à la tête, le déclin fonctionnel semblait comparable, qu'il y ait ou non présence d'une blessure concomitante ( $R R=1,35$ [IC à $95 \%$ : 0,71 à 2,59]).
Conclusion: Dans une population âgée autonome, la survenue d'un traumatisme à la tête ne semble pas être associée à un moins bon pronostic fonctionnel ou cognitif six mois plus tard, comparativement aux traumas mineurs sans blessure à la tête.

Keywords: head injury, minor trauma, elderly, cognitive status, functional outcomes

\section{INTRODUCTION}

The consequences of minor trauma involving a head injury (MT-HI) in independent older adults are largely unknown. Head injuries are a frequent reason for emergency department (ED) visits, representing about 50,000 visits annually in Canada. The great majority of these head injuries are qualified as minor or mild. ${ }^{1}$ There is an increasing awareness regarding the long-term impact of minor trauma involving head injuries (MT-HI) in all age groups. ${ }^{2,3}$ Long-term impact is associated with functional and cognitive status ${ }^{4}$, both of which are reported to be directly linked to patient independence ${ }^{5}$. However, there is a relative lack of data on long-term effect of this kind of trauma in the elderly population. ${ }^{5}$ This is of concern because the elderly population is aging and life expectancy is growing. ${ }^{6} \mathrm{We}$ are therefore likely to observe an increase in MT-HI in this population in the next few years. ${ }^{7}$

Data regarding MT-HI in the older population is scant. In a retrospective cohort study of 277 patients, Testa et al. studied the effects of age on recovery after a moderate or mild traumatic brain injury (mTBI) compared to an orthopedic injury. ${ }^{8}$ Their results suggested that patients 50-89 years of age, particularly those with mTBI, were significantly more dependent compared to younger patients, as measured with the Independent Living Scale (ILS) at one year post-injury. More recently, Sirois et al. and the CETI (the Canadian Emergency Departments Team Initiative) evaluated functional decline in older patients after different types of minor trauma, including MT-HI, ${ }^{9}$ and found that approximately $18 \%$ of their population had a functional decline at six months.

Furthermore, older adults often sustain more than one injury in the same event. ${ }^{10}$ Leong et al. studied the effect of a co-injury (injury to another part of the body) with a mTBI in young patients and found that their functional outcome was significantly worse than those without a co-injury. ${ }^{11}$

To our knowledge, no prospective study has attempted to assess the long-term impact of a MT-HI on the functional outcome of independent elderly patients compared to those with a minor trauma not involving the head. We hypothesized that MT-HI may impact functional and cognitive status among older adults discharged from the ED and that a concomitant injury could cause a more important decline in MT-HI patients.

\section{OBJECTIVE}

The main objective of this study was to assess the functional status in patients over 65 years of age, six months after a minor trauma including a head injury. The secondary objectives were to assess: 1 ) the cognitive status in patients over 65 years of age, six months after a minor trauma including a head injury, and 2) the effects of a concomitant injury on the functional outcomes of patients who sustained a MT-HI.

\section{METHODS}

\section{Population}

This prospective cohort study was conducted in eight Canadian teaching hospitals by the CETI. Patients included in our study were recruited between May 2009 and January 2014. Patients were included if they were: 1) aged 65 years or older, 2) presenting to the ED with a chief complaint of a minor traumatic injury within two weeks of injury, 3) discharged from the ED within 48 hours, and 4) independent in their basic activities of daily living prior to the $\mathrm{ED}$ visit, which was defined as a score equal or greater than 27 on the Older Americans' Resources and Services (OARS) scale ${ }^{12}$. Minor traumatic injuries were defined on the basis of the ED physician or research personnel evaluation as anatomical lesions which do not require hospitalization. The assessment and investigation of injury and the decision to hospitalize the patient were left to the discretion of the emergency physician in charge. Patients who occasionally used a walking aid and patients requiring outpatient surgeries after ED evaluation were also included. 
Functional outcome in elderly with minor head injury

Table 1. Baseline characteristics of participants $(n=926)$

\begin{tabular}{|c|c|c|}
\hline & $\begin{array}{c}\text { Patients with MT-HI } \\
\mathrm{n}(\%)\end{array}$ & $\begin{array}{l}\text { Patients without head injury } \\
\mathrm{n}(\%)\end{array}$ \\
\hline Total & 344 & 582 \\
\hline \multicolumn{3}{|l|}{ Age (years) } \\
\hline $64-74$ & $119(34.6)$ & 277 (47.6) \\
\hline $75-84$ & $156(45.4)$ & $231(39.7)$ \\
\hline$\geq 85$ & $69(20.1)$ & $74(12.7)$ \\
\hline Mean (SD) & $78.1(7.4)$ & $75.7(7.2)$ \\
\hline Men & $95(27.6)$ & $212(36.5)$ \\
\hline \multicolumn{3}{|l|}{ Number of comorbidities } \\
\hline $0-1$ & $51(14.9)$ & $87(15)$ \\
\hline $2-4$ & $148(43.3)$ & $252(43.3)$ \\
\hline $5-13$ & $143(41.8)$ & $243(41.7)$ \\
\hline \multicolumn{3}{|l|}{ Mechanism of injury } \\
\hline Simple fall & $242(71.6)$ & $349(61)$ \\
\hline Fall ( 1 to 10 meters) & $44(13)$ & 65 (11.4) \\
\hline Motor vehicle accident (MVA) & $15(4.4)$ & $23(4)$ \\
\hline Pedestrian vs.MVA & $4(1.2)$ & 0 \\
\hline Recreational vehicle accident & $4(1.2)$ & $19(3.3)$ \\
\hline Others & $29(8.6)$ & $116(23.6)$ \\
\hline \multicolumn{3}{|l|}{ Types of injury } \\
\hline Simple extremity fractures & $33(9.6)$ & $176(30.2)$ \\
\hline Rib fractures & $6(1.7)$ & $37(6.4)$ \\
\hline Sprain & $22(6.4)$ & $86(14.8)$ \\
\hline Shoulder dislocation & $1(0.3)$ & $4(0.7)$ \\
\hline Abrasion (extremities, thorax, abdomen) & $27(7.8)$ & $21(3.6)$ \\
\hline Laceration (extremities, thorax, abdomen) & $49(14.2)$ & $96(16.5)$ \\
\hline Contusion (extremities, thorax, abdomen) & $91(26.4)$ & $183(31.4)$ \\
\hline Spine fractures (including vertebral compression fractures) & $4(1.2)$ & $27(4.7)$ \\
\hline Mild traumatic brain injury (mTBI) & $179(52)$ & N/A \\
\hline MT-HI without $\mathrm{mTBI}$ & $165(48)$ & N/A \\
\hline Abrasion (head or face) & $34(20.6)$ & N/A \\
\hline Laceration (head or face) & $80(48.5)$ & N/A \\
\hline Contusion (head or face) & $73(44.2)$ & N/A \\
\hline Fracture (nose or face) & $25(15.2)$ & N/A \\
\hline Pain level $\geq 7 / 10$ & $34(10)$ & $90(15.6)$ \\
\hline \multicolumn{3}{|l|}{ Delay between time of injury and ED consultation } \\
\hline$<24 \mathrm{~h}$ & $260(75.6)$ & $333(57.2)$ \\
\hline $24-48 \mathrm{~h}$ & $26(7.6)$ & $74(12.7)$ \\
\hline$>48 \mathrm{~h}$ & $39(11.3)$ & $141(24.2)$ \\
\hline \multicolumn{3}{|l|}{ Social characteristics } \\
\hline Lives alone & $142(41.5)$ & $203(35.1)$ \\
\hline Social support index (SSI) $\geq 64 / 100$ & $272(80.7)$ & $462(80.8)$ \\
\hline$\geq 3$ general practitioner consultation in the last 3 months & $41(12.1)$ & $44(7.7)$ \\
\hline Emergency department visit in the last 3 months & $36(10.6)$ & $75(13)$ \\
\hline Falls in the last 3 months & $74(21.8)$ & $100(17.2)$ \\
\hline$<5$ outings/week & $99(29.8)$ & $154(27.3)$ \\
\hline Occasional use of a walking aid & $53(15.6)$ & $92(15.9)$ \\
\hline \multicolumn{3}{|l|}{ Identification of Seniors at Risk (ISAR) screening tool } \\
\hline 1. Regular help needed pre-injury & $18(5.3)$ & $35(6)$ \\
\hline 2. More help needed post- injury & $74(21.6)$ & $218(37.6)$ \\
\hline 3. Hospitalisation in the last 6 months & $25(7.3)$ & $45(7.8)$ \\
\hline 4. Good vision in general & $52(15.2)$ & $65(11.2)$ \\
\hline 5. Serious memory problems & $11(3.2)$ & $18(3.1)$ \\
\hline 6. Takes more than 6 meds/day & $134(40.1)$ & $190(33.2)$ \\
\hline
\end{tabular}


Participants were excluded if they 1) had significant injuries leading to any surgical or medical in-patient intervention, 2) were living in nursing homes or retirement homes with extra services, 3 ) were unable to consent, to attend follow-ups, or to communicate in French or English.

All patients were divided into two groups:

- Patients with MT-HI, which was defined as any trauma to the head, including scalp hematoma, facial fracture, contusion and laceration, with or without $m T B I$, as defined by the World Health Organization (WHO). ${ }^{13,14}$ In addition to their head injury, they could have sustained another injury elsewhere.

- Patients without head injury, which included patients with the following isolated injuries: simple extremity fractures, contusions, lacerations, and abrasions of any body part, except the head. The types of injury are described in Table 1.

Finally, patients included in the MT-HI group could have sustained other types of minor injuries (co-injury). To evaluate the effect of concomitant injury on functional decline, this group was divided into two subgroups: patients without any other injury and patients with one or several co-injuries.

\section{Data collection}

ED physicians screened all potential participants 24 hours a day and seven days a week. After a physical examination of patient injuries, physicians determined a patient's eligibility for inclusion in the study. Trained research assistants were onsite to conduct patient interviews and data collection using standardized data collection tools. Participants underwent a baseline evaluation and a follow-up evaluation at six months post-injury. The assessment of their functional status was done either in person $(20 \%)$ or by phone $(80 \%)$. Perceived pain level was also measured on a verbal scale from 0 to 10. Sociodemographic and clinical data, such as age, sex, mechanism of injury, medication use, comorbidities, falls in the last three months, and social status were collected during the interview. As well, the Identification of Seniors at Risk (ISAR) score, a screening tool which has been developed to predict clinical outcomes in acute clinical settings, was performed. All injuries were coded by trained professionals using the Abbreviated Injury Scale (AIS-2005), a validated diagnosis classification of injuries. ${ }^{15,16}$
The protocol was approved by the Research Ethics Review Board of the CHU de Québec and the ethics boards at each of the participating hospitals. Written or verbal consent was obtained for all participants.

\section{Outcomes measures}

The primary outcome was functional decline, which was measured by the OARS scale at baseline and six-months post-injury. This validated and reliable multidimensional functional assessment tool involves a 28-point scale that evaluates the ability to perform seven general activities (i.e., eating, grooming, dressing, transferring, walking, bathing, and continence) and seven activities of daily living (i.e., meal preparation, homemaking, shopping, using transportation, using the phone, managing medication, and managing money). ${ }^{12,17}$ Functional decline was defined as a loss of two points or more on the OARS scale, which is considered significant according to previous studies., ${ }^{9,18}$ This loss of two points may reflect a complete loss of one activity or a loss of one point in two different activities.

Cognitive function was measured using either the MoCA (Montreal Cognitive Assessment) or the TICS-m (modified Telephone Interview for Cognitive Status) at baseline and six months post-injury. If the research assistant was available in the ED, the MoCA was used. Otherwise, the evaluation was done by phone with the TICS-m. The MoCA is a validated 30-point tool that evaluates superior cerebral functions (i.e., executive function, naming, memory, attention, language, orientation, and abstraction) and has a Cronbach alpha of $0.83,{ }^{19}$ suggesting a high reliability. The TICS- $m$ is also a validated and standardized test that aims to evaluate the superior cerebral functions, and has a Cronbach alpha of $0.98 .^{20}$ According to the literature, a MoCA score of $<26 / 30$ or a TICS-m result of $<31 / 50$ would indicate a mild cognitive impairment. ${ }^{19,21}$

\section{Statistical analyses}

Data are presented as proportions and measures of central tendency, mean or median, and dispersion (standard deviation or inter-quartile range). An exploratory analysis of the socio-demographic characteristics was conducted to determine if there were significant independent predictors of functional decline. Multivariate analyses were used to estimate the relative risk of functional decline in the MT-HI group with a $95 \%$ confidence interval (CI). A $\log$ binomial model was used with adjustment for age, sex, and comorbidities. 


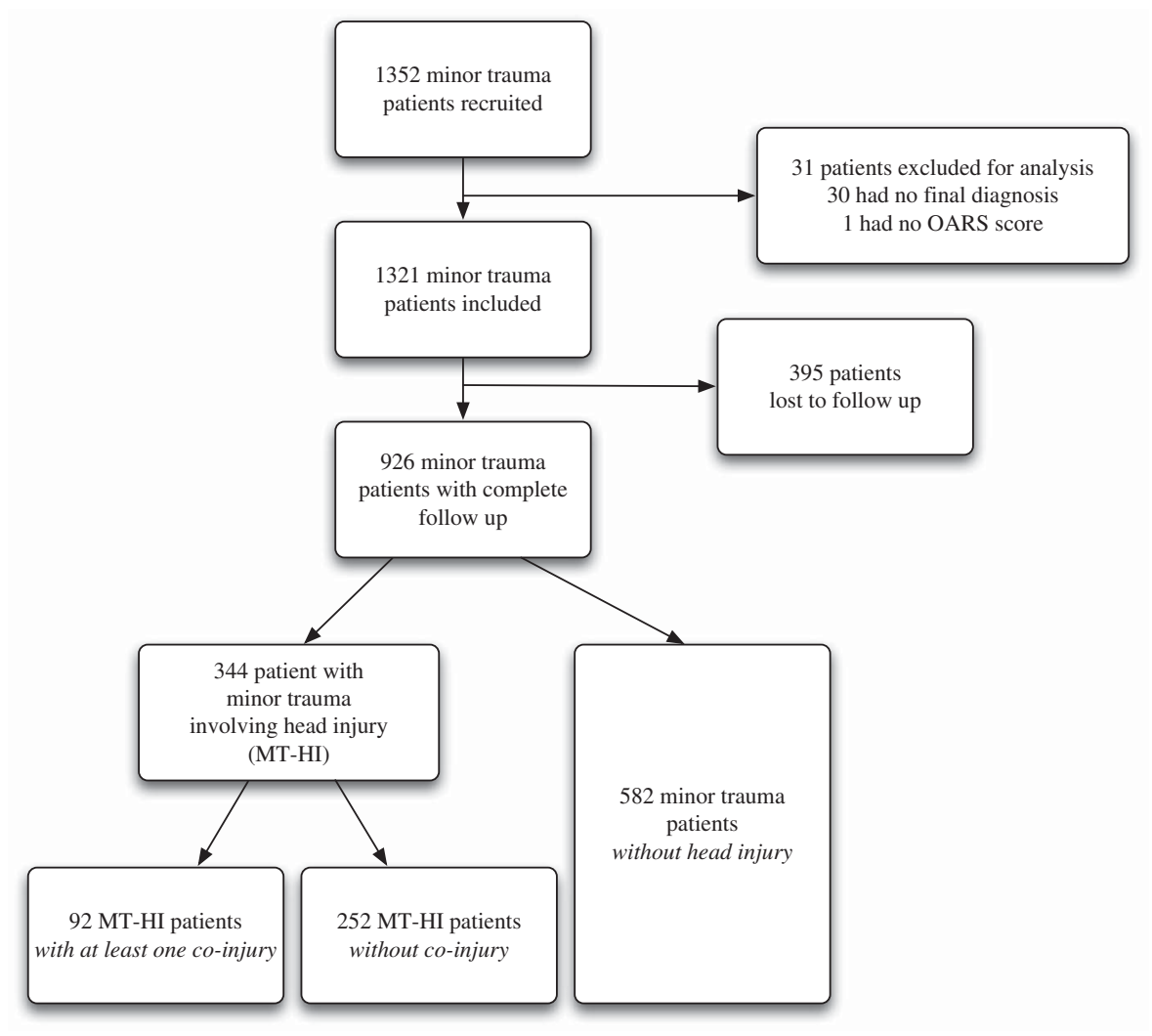

Figure 1. Flowchart of the study population.

Sensitivity analyses were done for sites as the recruitment occurred in eight different centers. Sensitivity analyses were performed to evaluate different cut-offs of the OARS scale and to evaluate the cognitive and functional decline of the mTBI population. We also compared mTBI (as defined by the WHO criteria $^{13,14}$ ) to patients with injuries other than mTBI.

With 926 patients, an alpha error of $5 \%$, and a power of $80 \%$, it was possible to detect an $8 \%$ difference of functional decline between the two groups. All analyses were completed using the Statistical Analysis System software (SAS Institute Cary, NC, USA, version 9.4).

\section{RESULTS}

A total of 926 patients were included in the analyses, 344 in the MT-HI group and 582 in the without head injury group (Figure 1). Although 395 of the 1,321 eligible patients did not complete the six-month followup, patients lost to follow-up were comparable to patients included in our analyses in terms of age, sex, comorbidities, type of injury, and mechanism of injury (Appendix 1).
Table 1 describes the characteristics of the participants and highlights some differences between the two groups. Patients with MT-HI were older than those without head injury. Also, falls from their own height was the leading cause of trauma in both groups but a greater proportion was found in the MT-HI group. A greater proportion of patients with a pain level $>7 / 10$ was identified in the without head injury group. Two important differences were found: patients from the without head injury group needed more help after their injury and they also had a greater proportion of consultation delays (time between injury and presentation at the ED) of 48 hours and more.

Six months after trauma, $10.8 \%$ of patients in the MT-HI group had a functional decline compared to $11.9 \%$ in the without head injury group ( $\mathrm{RR}=$ 0.79 [95\% CI $0.55-1.14]$ ), which was not statistically significant (Table 2). The proportion of participants who had mild cognitive impairment was similar in the two groups both at baseline (RR $=1.01$ [95\% CI $0.84-1.30]$ ) and at six months post-injury ( $\mathrm{RR}=$ $0.91[0.71-1.18])$. Surprisingly, at six months, the proportion of patients who had a cognitive impairment 


\begin{tabular}{|c|c|c|c|}
\hline & $\begin{array}{l}\text { Patients with MT-HI } \\
\qquad \begin{array}{c}n=344 \\
n(\%)\end{array}\end{array}$ & $\begin{array}{l}\text { Patients without head injury } \\
\qquad \begin{array}{c}n=582 \\
n(\%)\end{array}\end{array}$ & $\mathrm{RR}^{*}(95 \% \mathrm{Cl})$ \\
\hline $\begin{array}{l}\text { Functional decline at } 6 \text { months ( } \geq 2 \text { points drop } \\
\text { on OARS scale)* }\end{array}$ & 37 (10.8) & 69 (11.9) & $0.79(0.55-1.14)$ \\
\hline \multicolumn{4}{|l|}{ MoCA $<26$ or TICS $\leq 31$} \\
\hline At baseline & $115(35.0)$ & $186(33.0)$ & $1.01(0.84-1.130)$ \\
\hline At 6 months & $68(21.7)$ & $123(22.8)$ & $0.91(0.71-1.18)$ \\
\hline
\end{tabular}

MT-HI = minor trauma involving head injury; OARS = Older Americans' Resources and Services; MoCA = Montreal Cognitive Assessment scale;

TICS = Telephone Interview for Cognitive Status. ${ }^{*}$ Relative risk are obtained from a log-binomial model adjusted for age, gender, and number of comorbidities.

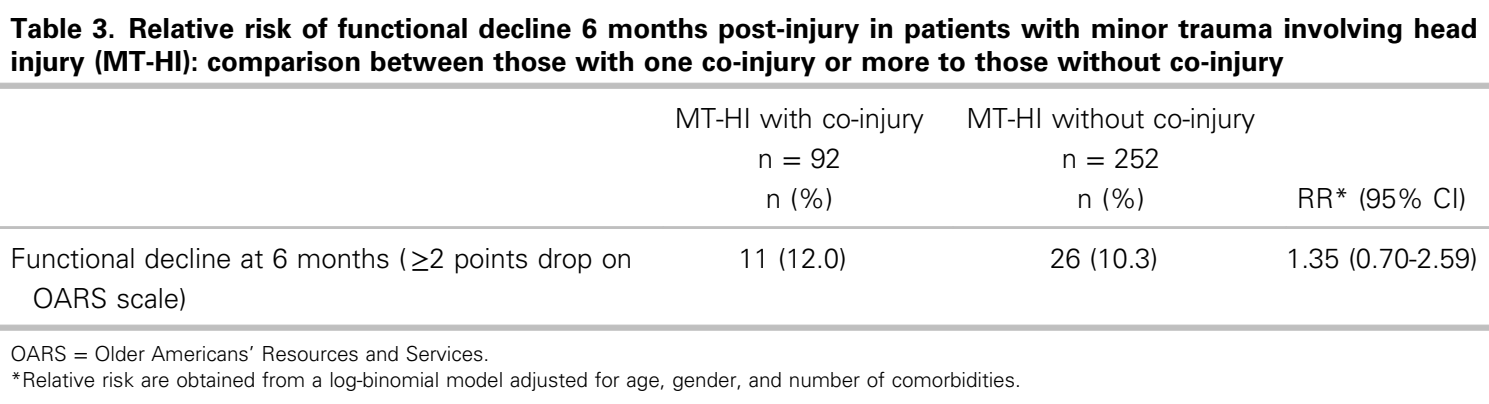

\begin{tabular}{|c|c|c|c|}
\hline & $\begin{array}{l}\text { Patients with mTBI } \\
\qquad \begin{array}{l}n=179 \\
n(\%)\end{array}\end{array}$ & $\begin{array}{l}\text { Patients without } \mathrm{mTB} \mathrm{I}^{* *} \\
\qquad \mathrm{n}=747 \\
\mathrm{n}(\%)\end{array}$ & $\mathrm{RR}(95 \% \mathrm{Cl})$ \\
\hline $\begin{array}{l}\text { Functional decline at } 6 \text { months ( } \geq 2 \text { points drop on } \\
\text { OARS scale) }\end{array}$ & $21(11.7)$ & $85(11.4)$ & $0.90(0.58-1.39)$ \\
\hline \multicolumn{4}{|l|}{ MoCA $<26$ or TICS $\leq 31$} \\
\hline At baseline & $60(34.7)$ & $241(33.5)$ & $0.96(0.77-1.19)$ \\
\hline At 6 months & $33(20.4)$ & $158(22.9)$ & $0.82(0.59-1.13)$ \\
\hline \multicolumn{4}{|c|}{$\begin{array}{l}\text { OARS = Older Americans' Resources and Services; MoCA = Montreal Cognitive Assessment scale; TICS = Telephone Interview for Cognitive Status. } \\
\text { *As defined by the World Health Organisation (WHO); one or more of these criteria: } 1 \text { ) any loss of consciousness of up to } 30 \text { minutes, 2) any loss of memory of the } \\
\text { events immediately before or after the accident for as much as } 24 \text { hours, 3) any alteration of mental state at the time of the accident, 4) transient focal neurologic } \\
\text { deficit, 5) post traumatic amnesia persisting for less than } 24 \text { hours, }, \text { a a score of } 13-15 \text { on the Glasgow Coma Scale (GCS) } 30 \text { minutes after trauma. } \\
\text { **Including 1) patients with minor trauma involving head injury (MT-HI) without mTBI, and 2) minor trauma patients without any head injury. } \\
\text { Relative Risk are obtained from a log-binomial model adjusted for age gender and number of comorbidities. }\end{array}$} \\
\hline
\end{tabular}

was lower than at baseline in both groups, $21.7 \% \mathrm{v}$. $35 \%$, and $22.8 \%$ v. $33 \%$ respectively $(p<0.001)$. The presence of a co-injury did not have a significant impact on functional decline in the MT-HI group (RR = 1.35 [95\% CI 0.70-2.59]) (Table 3).

We performed a subgroup analysis comparing mTBI patients, as defined by the WHO criteria, to patients with injuries other than mTBI (Table 4). The proportion of patients who had a functional decline was $11.7 \%$ in the mTBI group v. $11.4 \%$ in the group without mTBI ( $\mathrm{RR}=0.90$ [95\% CI 0.58-1.39]). We found no significant difference in cognitive outcomes at six months between these two subgroups $(20.4 \% \mathrm{v}$. $22.9 \%, \mathrm{RR}=0.82$ [95\% CI 0.59-1.13]). Sensitivity analyses with different cut-offs for the OARS scale did not show different results (data not shown). 


\section{DISCUSSION}

To our knowledge, this is the first prospective study aiming to compare the functional prognosis of older adults after a MT-HI with those who sustained a minor trauma without a head injury. Our study included elderly patients from a large Canadian multicenter cohort, and standardized validated scales were used to assess outcomes. Our results showed that functional and cognitive decline was similar in both groups. So we can expect a similar prognosis regardless of the nature of the injury.

Approximately $11 \%$ of our independent older adults did suffer from a functional decline after a minor trauma. This is of concern and raises many questions. Is a minor trauma a cause or a consequence of functional decline? Probably both. We assumed that a small fracture, an abrasion, or a MT-HI would be resolved after six months, but our results showed that the functional decline was persistent in an important proportion of patients.

Our initial hypothesis was that a minor trauma involving a head injury (MT-HI) could have a more significant impact on functional outcome than a minor trauma without a head injury. However there were no differences between the two groups six months after the trauma. Surprisingly, the cognitive status at six months improved relative to baseline for all patients, which correlates with results of a previous study ${ }^{22}$ on this subject. A hypothesis that could explain this finding is that the tests were done after the actual injury and their results might not represent the real baseline cognitive status of participants before the trauma. In addition, it has been shown that a short visit to the ED has repercussions on the cognitive status (recognised as delirium) of elderly patients. $^{22-26}$ Another hypothesis is that the presence of a potential overestimation of their function by the patients who had follow-up by phone (80\%) rather than face-toface follow-up. However, this bias would be a nondifferential bias, so it would not advantage one group more than the other regarding the outcomes.

In regard to co-injuries, our results did not show a worse functional outcome among patients with a MT-HI and a co-injury, compared to a previous study by Leong et al. ${ }^{11}$ However, the study populations were different in terms of age and injury severity.

Our study had several limitations. One limitation was the potential selection bias caused by the non-consecutive recruitment of patients. ED overcrowding and availability of the research assistants partially explains our recruitment design. Data on the missed cases due to scheduling were not available; however, no obvious selection bias occurred because patients were not recruited based on particular sociodemographic characteristics or based on specific injury type. Moreover, sensitivity analyses did not show differences between recruitment sites.

Another limitation introducing a potential selection bias was the number of participants lost to follow-up: $29 \%$ of our cohort was not reassessed on the main study outcomes at six months. This could be explained by the fact that our population was older and therefore it was more difficult for them to come back to the hospital for follow-up or to complete the entire questionnaire by phone. As previously mentioned, there were no differences in socio-demographic or clinical characteristics between the population lost to follow-up and our participants (Appendix 1). Therefore, we don't think that a serious bias affected our results.

Although this is a large cohort, this study might not have enough power to show a statistically significant difference between the two groups for the main outcome. since the calculation of the sample size was based on a study with a higher prevalence $(18 \%)$ of functional decline. ${ }^{9}$ However, we considered that the observed difference of functional decline between patients with or without MT-HI was not clinically important (1.1\%). Finally, we were well aware that the standardized and validated tests used to measure cognitive outcomes might not be sensitive enough to detect a significant functional decline. Some authors have proposed a drop of three points instead of two as a cut-off on the OARS scale. ${ }^{27}$ However, our sensitivity analyses using different cut-offs on the OARS scale did not show any difference in the results.

One of the strengths of this study was the definition we used for the MT-HI group: any trauma to the head, including scalp hematoma, facial fracture, contusion, and laceration, with or without mTBI. Indeed, the diagnosis of mTBI in older patients remains a challenge. ${ }^{5}$ Factors such as age-induced cerebral atrophy, and physiological response to a trauma can potentially hide typical symptoms of mTBI and undermine the reliability of the GCS. ${ }^{28}$ These patients may not always present with the typical symptoms of mTBI but may nevertheless suffer significant consequences. ${ }^{29,30}$ An extensive review of the literature was conducted in order to find an appropriate definition of minor head trauma without brain injury. Some authors 
have suggested the term "minimal traumatic head injury" to define a head trauma with a GCS score of 15 without any brain injury (i.e. no altered state of consciousness). ${ }^{31}$

Because the assessment of elderly patients presenting with head injury in the context of a minor trauma is challenging, the MT-HI definition was more inclusive than other definitions previously used for research on head trauma in older adults. Our conclusions therefore likely extend to all patients with a minor trauma involving a head injury, with or without mTBI.

Finally, emergency physicians often consider head trauma as a serious threat to functional prognosis in patients. This study reveals that minor trauma, with or without head injury, could significantly affect the functional outcome for older patients. These results can inform clinicians that the location of injury (head $v$. other) does not seem to affect the functional outcome. This information will help emergency physicians to correctly assess elderly patients with a minor trauma.

\section{CONCLUSION}

Older independent adults with a minor trauma involving a head injury do not seem to have worse functional or cognitive decline than those without head injury. In our MT-HI group, the presence of a concomitant injury did not seem to be associated with an increased risk of functional decline after six months. Although we observed a similar prognosis regardless of the nature of the injury, $11 \%$ of our cohort of independent older adults had a significant functional decline following their minor traumatic injury. Accordingly, further research should focus on finding a way to effectively screen for patients who are at higher risk of functional decline.

Acknowledgements: The authors want to thank all emergency physicians of the eight participating Canadian teaching hospitals. We would also like to thank Xavier Neveu and Brice Lionel Batomen Kuimi for their valuable assistance with statistical analysis.

\section{SUPPLEMENTARY MATERIAL}

To view supplementary material for this article, please visit http://dx.doi.org/10.1017/cem.2016.368

\section{REFERENCES}

1. Brain Injury Society of Toronto. Facts about ABI. 2015. Available at: http://www.bist.ca/facts-about-abi/ (accessed 3 November 2015).

2. Andersson EE, Bedics BK, Falkmer T. Mild traumatic brain injuries: a 10-year follow-up. 7 Rebabil Med 2011;43(4): 323-9.

3. Katz DI, White DK, Alexander MP, et al. Recovery of ambulation after traumatic brain injury. Arch Phys Med Rebabil 2004;85(6):865-9.

4. Kessler C, Williams MC, Moustoukas JN, et al. Transitions of care for the geriatric patient in the emergency department. Clin Geriatr Med 2013;29(1):49-69.

5. Callaway DW, Wolfe R. Geriatric trauma. Emerg Med Clin North Am 2007;25(3):837-60, x.

6. Marx JA, Hockberger RS, Walls RM, et al. Rosen's Emergency Medicine:Concepts and Clinical Practice, 7th ed. Philadelphia: Mosby Elsevier; 2010.

7. Depreitere B, Meyfroidt G, Roosen G, et al. Traumatic brain injury in the elderly: a significant phenomenon. Acta Neurochir Suppl 2012;114:289-94.

8. Testa JA, Malec JF, Moessner AM, et al. Outcome after traumatic brain injury: effects of aging on recovery. Arch Phys Med Rehabil 2005;86(9):1815-23.

9. Sirois MJ, Emond M, Ouellet MC, et al. Cumulative incidence of functional decline after minor injuries in previously independent older Canadian individuals in the emergency department. I Am Geriatr Soc 2013;61(10): 1661-8.

10. Tintinalli JE, Stapczynski JS. Tintinalli's Emergency Medicine: A Comprehensive Study Guide. New York: McGraw-Hill; 2011.

11. Leong BK, Mazlan M, Abd Rahim RB, et al. Concomitant injuries and its influence on functional outcome after traumatic brain injury. Disabil Rehabil 2013;35(18):1546-51.

12. McCusker J, Bellavance F, Cardin S, et al. Validity of an activities of daily living questionnaire among older patients in the emergency department. 7 Clin Epidemiol 1999;52(11): 1023-30.

13. Rehabilitation ACo. Definition of mild traumatic brain injury: Report of the Mild Traumatic Brain Injury Committee of the head Injury Interdisciplinary Special Interest Group of the American Congress of Rehabilitation Medicine. 7 Head Trauma Rebabil 1993;8:86-7.

14. Cancelliere C, Cassidy JD, Li A, et al. Systematic search and review procedures: results of the International Collaboration on Mild Traumatic Brain Injury Prognosis. Arch Phys Med Rehabil 2014;95(3 Suppl):S101-1.

15. Joosse $\mathrm{P}$, de Jongh MA, van Delft-Schreurs CC, et al. Improving performance and agreement in injury coding using the Abbreviated Injury Scale: a training course helps. HIM 7 2014;43(2):17-22.

16. Lopes MC, Whitaker IY. Measuring trauma severity using the 1998 and 2005 revisions of the abbreviated injury scale. Rev Esc Enferm USP 2014;48(4):640-7.

17. Fillenbaum GG, Smyer MA. The development, validity, and reliability of the OARS multidimensional functional assessment questionnaire. 7 Gerontol 1981;36(4):428-34. 
18. Hebert R, Bravo G, Korner-Bitensky N, et al. Predictive validity of a postal questionnaire for screening communitydwelling elderly individuals at risk of functional decline. Age Ageing 1996;25(2):159-67.

19. Fujiwara Y, Suzuki H, Yasunaga M, et al. Brief screening tool for mild cognitive impairment in older Japanese: validation of the Japanese version of the Montreal Cognitive Assessment. Geriatr Gerontol Int 2010;10(3):225-32.

20. Beeri MS, Werner P, Davidson M, et al. Validation of the modified telephone interview for cognitive status (TICS-m) in Hebrew. Int 7 Geriatr Psychiatry 2003;18(5): 381-6.

21. Knopman DS, Roberts RO, Geda YE, et al. Validation of the telephone interview for cognitive status-modified in subjects with normal cognition, mild cognitive impairment, or dementia. Neuroepidemiology 2010;34(1):34-42.

22. Ouellet MC, Sirois MJ, Beaulieu-Bonneau S, et al. Is cognitive function a concern in independent elderly adults discharged home from the emergency department in Canada after a minor injury? 7 Am Geriatr Soc 2014;62(11): 2130-5.

23. Elie M, Rousseau F, Cole M, et al. Prevalence and detection of delirium in elderly emergency department patients. CMA7 2000;163(8):977-81.

24. Hustey FM, Meldon SW. The prevalence and documentation of impaired mental status in elderly emergency department patients. Ann Emerg Med 2002;39(3):248-53.
25. Kakuma R, du Fort GG, Arsenault L, et al. Delirium in older emergency department patients discharged home: effect on survival. 7 Am Geriatr Soc 2003;51(4):443-50.

26. Kennedy M, Enander RA, Tadiri SP, et al. Delirium risk prediction, healthcare use and mortality of elderly adults in the emergency department. 7 Am Geriatr Soc 2014;62 (3):462-9.

27. Abdulaziz K, Brehaut J, Taljaard M, et al. National Survey of Emergency Physicians to Define Functional Decline in Elderly Patients with Minor Trauma. CFEM 2015;17(6):63947.

28. Stiell IG, Clement CM, Rowe BH, et al. Comparison of the Canadian CT Head Rule and the New Orleans Criteria in patients with minor head injury. FAMA 2005;294(2): 1511-8.

29. Bouida W, Marghli S, Souissi S, et al. Prediction value of the Canadian CT head rule and the New Orleans criteria for positive head CT scan and acute neurosurgical procedures in minor head trauma: a multicenter external validation study. Ann Emerg Med 2013;61(5):521-7.

30. BMJ. BMJ Best Practice. British Medical Journal; 2014. Available at: http://bestpractice.bmj.com/best-practice/ monograph/515.html (accessed 3 November 2015).

31. Unden J, Ingebrigtsen $\mathrm{T}$, Romner $\mathrm{B}$, et al. Scandinavian guidelines for initial management of minimal, mild and moderate head injuries in adults: an evidence and consensusbased update. BMC Med 2013;11:50. 